\title{
IEEE TRANSACTIONS ON
}

\section{GEOSCIENCE AND REMOTE SENSING}

A PUblication OF the IEEe GEOSCIENCE AND REMOTE SENSING SOCIETY

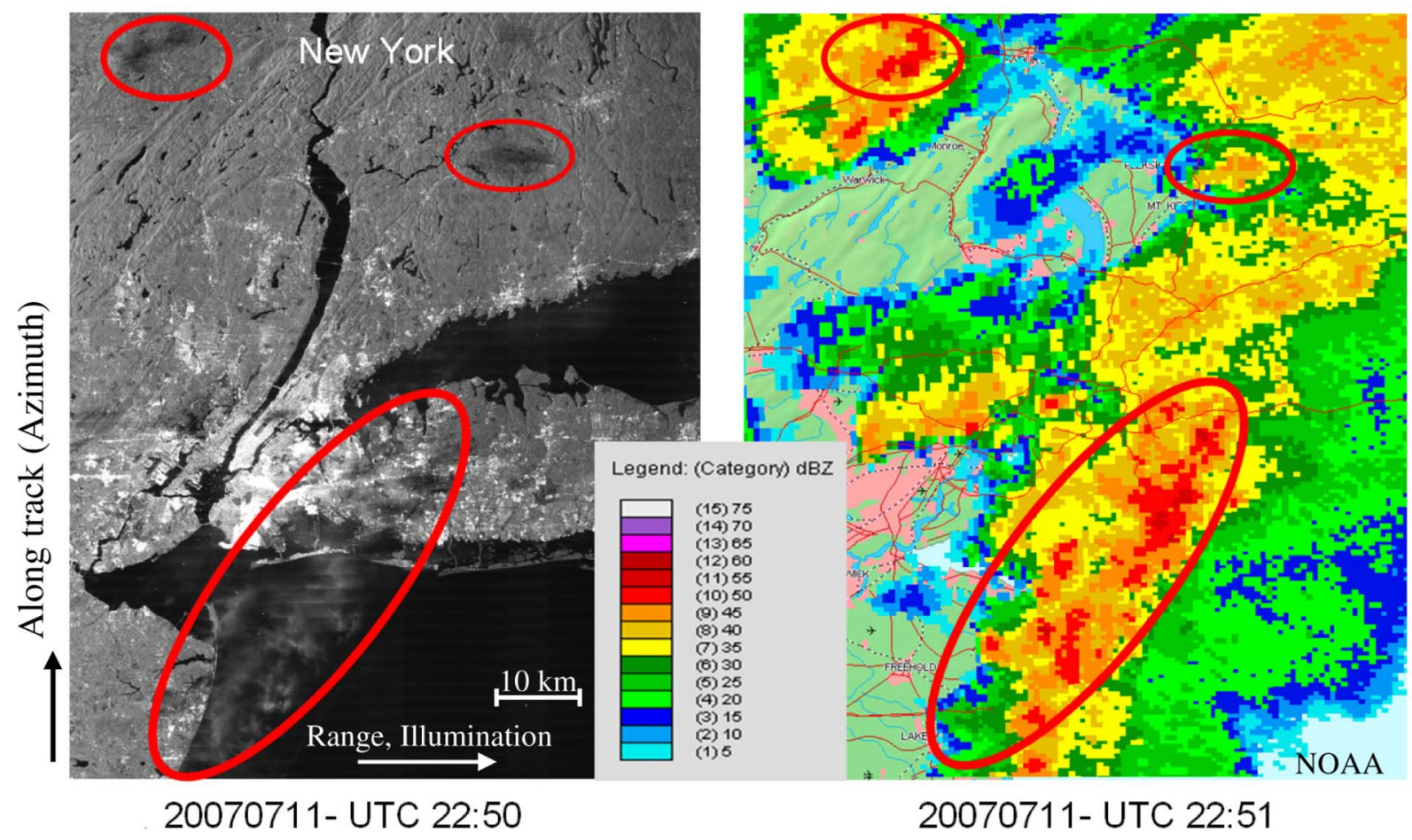

A test case showing a comparison of TerraSAR-X and ground-based weather radar data acquired nearly simultaneously (within the same minute) over

New York City. A good agreement between rain-cell signatures in (left) the SAR image and (right) the weather radar image can be observed.

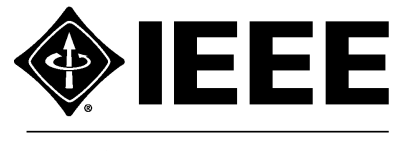




\title{
Assessment of Atmospheric Propagation Effects in SAR Images
}

\author{
Andreas Danklmayer, Member, IEEE, Björn J. Döring, Marco Schwerdt, and Madhu Chandra
}

\begin{abstract}
TerraSAR-X, the first civil German synthetic aperture radar (SAR) satellite, was successfully launched on June 15, 2007. After 4.5 days, the first processed image was obtained. The overall quality of the image was outstanding; however, suspicious features could be identified which showed precipitation-related signatures. These rain-cell signatures are thoroughly investigated, and the physical background of the related propagation effects is provided. In addition, rain-cell signatures from former missions like SIR-C/X and the Shuttle Radar Topography Mission are provided for comparison. During the commissioning phase of TerraSAR-X, a total of 12000 scenes were investigated for potential propagation effects, and about 100 scenes revealed atmospheric effects to a visible extent. Some of the particularly interesting events were selected and are discussed in greater detail. An interesting case of data acquisition over New York will be presented, which shows typical rain-cell signatures, and the SAR image will be compared with weather-radar data acquired nearly simultaneously (within the same minute). By comparing the images, it can be clearly seen that reflectivities in the weather-radar image of $50 \mathrm{dBZ}$ may cause visible artifacts in SAR images. Furthermore, in this paper, we discuss the influence of the atmosphere (troposphere) on the external calibration of TerraSAR-X. By acquiring simultaneous weather-radar data over the test site and the SAR acquisition, it was possible to flag affected SAR images and to exclude them from the procedure to derive the absolute calibration constant. Thus, it was possible to decrease the $1 \sigma$ uncertainty of the absolute calibration factor by $0.15 \mathrm{~dB}$.
\end{abstract}

Index Terms-Attenuation, propagation, rain, synthetic aperture radar (SAR), TerraSAR-X.

\section{INTRODUCTION}

$\mathbf{M}$ ICROWAVE imaging of the Earth's surface using spaceand airborne synthetic aperture radar (SAR) systems is sometimes considered to be independent of weather conditions and the actual state of the atmosphere. In fact, we have to clearly underline that radar satellites such as TerraSAR-X offer the advantage of imaging capability even in case of clouds (low or nonprecipitating) and during night time, which is generally in contrast to optical systems.

However, the propagation media along the propagation path, in particular convective precipitation with high intensity, may significantly impair SAR images or parts of it. For the analysis of atmospheric effects, the atmosphere is conveniently subdi-

Manuscript received October 10, 2008; revised March 13, 2009. First published July 7, 2009; current version published September 29, 2009.

A. Danklmayer, B. J. Döring, and M. Schwerdt are with the Microwaves and Radar Institute, German Aerospace Center (DLR), 82234 Oberpfaffenhofen, Germany (e-mail: andreas.danklmayer@ dlr.de).

M. Chandra is with the Department of Microwave Engineering and Photonics, Chemnitz University of Technology, 09126 Chemnitz, Germany.

Color versions of one or more of the figures in this paper are available online at http://ieeexplore.ieee.org.

Digital Object Identifier 10.1109/TGRS.2009.2022271 vided into two major regimes (layers), i.e., the ionosphere and the troposphere. Among the many effects, which may occur in these two regimes, are delays, attenuation, noise, scintillations, and depolarization which are caused by atmospheric gases, rain (precipitation), clouds, fog, or free electrons in the ionosphere. Whether these effects are relevant depends on the signal parameters, the path geometry, and the conditions prevailing in the ionosphere and the troposphere. As will be shown later, the use of higher frequencies (X-band and beyond) minimizes ionospheric effects on propagation, but tropospheric effects often increase or dominate.

The intention of this paper is to review and identify the major effects and investigate their relevance for the case of TerraSAR-X and to show when and to what quantitative extent the atmosphere is affecting the measurements. Furthermore, it is the intention to provide some underlying physical background of the effects, particularly the reflection and attenuation due to precipitation. During the planning activities for the external calibration (XCAL) campaign taking place in the fivemonth-long commissioning phase of TerraSAR-X, it became evident that the precipitation effects have to be taken into account in order to maximize the accuracy of the absolute calibration factor. The essential task of the XCAL is the measurement of the whole SAR system against standard ground targets. Thus, by evaluating the SAR images depicting these ground target responses, the absolute calibration factor can be derived. By using this factor, the processor performs a bias correction resulting in absolutely calibrated SAR data products.

This paper is organized as follows. In Section II, we briefly address the issue of ionospheric effects in SAR imaging and limit ourselves to a succinct summary with conclusion, since they are of minor relevance for frequencies above $3 \mathrm{GHz}$ under regular ionospheric conditions. Furthermore, they are well documented by recent publications provided in Section II. In Section III, we discuss the most relevant tropospheric effects for microwave SAR imaging and the electromagnetic properties of the tropospheric layer. Furthermore, statistical aspects of precipitation and attenuation are highlighted, where the annual probability of rain and attenuation is provided. In Section IV, it is shown how the atmosphere affects multimodal SAR applications for implementation by spaceborne instruments with respect to X-, C-, and L-band frequencies. The discussion of propagation effects is reinforced with appropriate data samples from previous missions like the SIR-C/X mission [1] and the Shuttle Radar Topography Mission (SRTM) [2].

Section V illustrates recent examples of TerraSAR-X images, showing exceptionally strong attenuating precipitation volumes, e.g., over rain forest, urban areas, and sea surfaces. Furthermore, Section V provides a physical explanation of visible artifacts in SAR images and then shows an interesting 
comparison between weather-radar data and SAR data acquired nearly simultaneously (within the same minute). It closes with a discussion on how the disadvantage of rain features in SAR imagery may turn out to be a useful source for assessing precipitation intensity over SAR-imaged areas. Section VI addresses the influence of the atmosphere on spaceborne TerraSAR-X XCAL and how the uncertainty of the absolute calibration factor was decreased by paying attention to atmospheric data in the procedure to derive the absolute calibration constant. In Section VII, the conclusions highlighting the key results are given, together with an outlook of new scientific challenges resulting from the presented scientific work.

\section{IONOSPHERIC EFFECTS}

In this section, we aim to briefly review and summarize the ionospheric effects influencing spaceborne SAR measurements. The ionosphere is the part of the upper atmosphere, which may significantly affect radio wave propagation due to its ionization. In essence, this shell ranges from approximately 60 to $1000 \mathrm{~km}$ in height. Unlike the troposphere, the ionosphere is ionized by the sun's ultraviolet and X-ray radiation, which results in free electrons. The density and concentration of the electrons highly depend on the time of day, location, and season. The ionospheric effects on microwave radiation are scintillation, Faraday rotation (FR), refraction, diffraction, absorption, noise emission, ohmic losses, phase delays, spectrum spreading, and defocusing. They are dependent on the signal properties like the frequency, polarization, amplitude, bandwidth, and modulation. In general, higher ionospheric electron density and lower microwave frequencies result in intensified effects.

Of special relevance for lower SAR frequencies $(<3 \mathrm{GHz})$ is FR [5]-[7]. The required parameters to characterize the propagation conditions are a strong function of the temporal and spatial scale. They depend on the global geomagnetic longitude and latitude with respect to the relative sun position. As the FR angle is proportional to $1 / f^{2}$, radar signals of short wavelengths (above approximately $3 \mathrm{GHz}$ ) experience minor rotation. In particular, the FR rotation at X-band (e.g., TerraSAR-X) is about 60 times lower than that at L-band (e.g., ALOS-PALSAR). At X-band, the FR is below $0.5^{\circ}$, which is negligible for most applications.

\section{A. Conclusions for Ionospheric Effects}

The general statement is that ionospheric effects have a larger impact with higher electron densities and lower frequencies. In particular, FR due to the ionosphere is without relevance for microwave imaging systems operating at frequencies above $3 \mathrm{GHz}$, but it may deteriorate image quality at lower frequencies, particularly at P- and L-bands under adverse ionospheric conditions.

\section{TROPOSPHERIC EFFECTS}

The troposphere, as the lowest part of the Earth's atmosphere, reaches from the surface to approximately $12 \mathrm{~km}$ above ground and causes, among other effects, attenuation of traversing signals due to hydrometeors (rain, snow, and hail), atmospheric gases, fog, and clouds [8]-[10]. Except for low elevation angles, the attenuation of frequencies below $1 \mathrm{GHz}$ is negligible. Insignificant contributions to the attenuation will be obtained
TABLE I

RAIN RATE AND SPECIFIC ATTENUATION FOR THE FREQUENCY BANDS L, C, AND X [17]. The DSDs Which WERE UsED ARE THE MARSHALL-PALMER (MP) AND THE JOSS-THUNDERSTORM (J-T)

\begin{tabular}{|c|c|c|c|c|}
\hline \multirow{2}{*}{$\begin{array}{c}\text { Rain rate } \\
{[\mathbf{m m} / \mathbf{h r}]}\end{array}$} & \multirow{2}{*}{ DSD } & \multicolumn{3}{|c|}{ Specific Attenuation $[\mathbf{d B} / \mathbf{k m}]$} \\
\cline { 3 - 5 } & & $\begin{array}{c}\text { L-band } \\
(1,5 \mathrm{GHz})\end{array}$ & $\begin{array}{c}\mathbf{C} \text {-band } \\
(6 \mathrm{GHz})\end{array}$ & $\begin{array}{c}\mathbf{X} \text {-band } \\
(10 \mathrm{GHz})\end{array}$ \\
\hline 2.5 & $\mathrm{MP}$ & $<0.001$ & $<0.01$ & 0.032 \\
\hline 12.5 & $\mathrm{MP}$ & $<0.001$ & 0.032 & 0.24 \\
\hline 50 & $\mathrm{~J}-\mathrm{T}$ & $<0.01$ & 0.36 & 1,29 \\
\hline 80 & $\mathrm{~J}-\mathrm{T}$ & $<0.01$ & 0.82 & 2,14 \\
\hline 150 & $\mathrm{~J}-\mathrm{T}$ & $<0.01$ & 1.5 & 4,23 \\
\hline
\end{tabular}

for frequencies up to $10 \mathrm{GHz}$ due to fog and nonprecipitating clouds. However, the transmission spectrum exhibits peaks for frequencies around 22 and $60 \mathrm{GHz}$ due to molecular resonances from gases, i.e., water vapor and oxygen. Whereas absorption effects due to atmospheric gases are present constantly and everywhere, attenuation due to condensed water in the form of precipitation, clouds, and fog is infrequent and is limited to certain areas. Attenuation consists of two physical processes: the reduction of the wave's energy due to the heating of the water particles and the scattering of energy away from the main direction of propagation. In Section III-A, we provide a discussion on attenuation through rain. Attenuation by snow, fog, and gases can be found in more detail in [9], [11]-[14].

\section{A. Rain Attenuation}

One of the major problems affecting microwave and millimeter-wave bands for terrestrial and spaceborne radars is the attenuation through rain [15], [16]. Rain is the most important cause, not only due to the strong attenuation effect but also due to the fact that rain occurs most frequently. In order to describe the attenuation through rain, a more detailed knowledge of the physical mechanism and a further analysis of the associated rain parameters are required. A convenient way to describe rain intensity is the so-called rainfall rate or rain rate given in millimeters per hour. This quantity refers to a certain flux of rain toward the surface of the Earth and may be measured by gauges on the surface. A rain rate of $4 \mathrm{~mm} / \mathrm{h}$ is a typical value for the specification of moderate rain [10]. Typical values for the specific attenuation (attenuation for 1$\mathrm{km}$ propagation path) of different frequency bands according to a given rain rate are provided in Table I [8], [17]. In many publications, an empirical relation of the form

$$
\gamma(x, t)=a R^{b}
$$

between specific attenuation $\gamma(x, t)$ and rain rate $R$ is provided [14], [17], [18]. The parameters $a$ and $b$ are dependent on the radio frequency, the raindrop size distribution (DSD), the signal polarization, and other factors [18].

In Fig. 1, a plot of the specific attenuation versus the rain rate for 1-, 6-, and 10-GHz frequencies is given. The depicted values have been calculated using ITU Recommendation 838 [8]. After [14], the two-way attenuation for a given instant of time can be obtained by integrating the specific attenuation along the path of propagation using the following expression:

$$
A(t)=\int_{0}^{2 h} \gamma(x, t) d x
$$




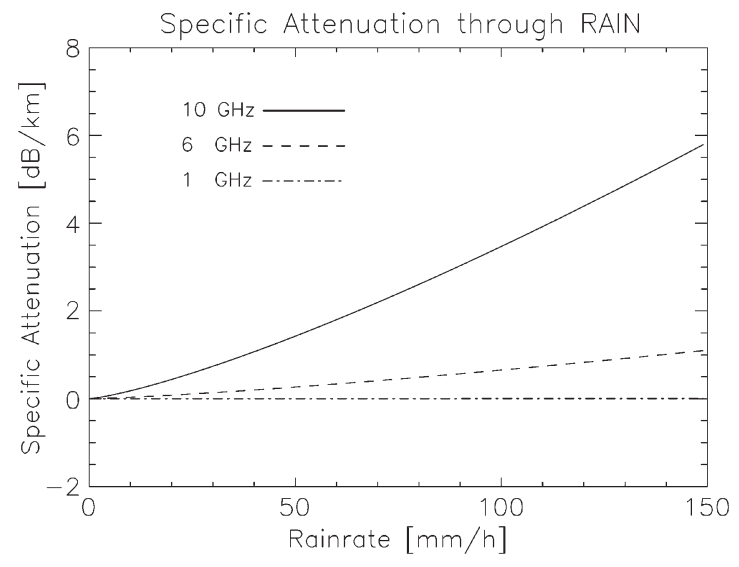

Fig. 1. Specific attenuation $[\mathrm{dB} / \mathrm{km}]$ of $\mathrm{EM}$ waves versus rain rate $[\mathrm{mm} / \mathrm{h}]$ for three different radar frequencies of 10,6 , and $1 \mathrm{GHz}$ [8].

where

$\begin{array}{ll}A(t) & \text { total attenuation for a given time instant } t \\ t & \text { time; } \\ h & \text { path length; } \\ \gamma(x, t) & \text { specific attenuation; } \\ x & \text { position along the path of propagation. }\end{array}$

The specific attenuation along the slant path of propagation has to be known. However, detailed knowledge of the medium through which the signal propagates is rather limited, and the temporal and spatial variations of the medium require assumptions and some modeling [10]. In the case of precipitation, we may have some idea about the thermodynamic phase (ice, water, and melting band) but no precise information.

The tabulated values for the attenuation in X-band (Table I) are now used to perform a simple calculation of the pathintegrated attenuation for a propagation scenario with a raincell height of $5 \mathrm{~km}$. For an incidence angle of $45^{\circ}$, a two-way propagation path of approximately $14 \mathrm{~km}$ will be traversed by the signals. For a heavy tropical convective rain $(80 \mathrm{~mm} / \mathrm{h}$ and more), this will result in a path-integrated attenuation of $30 \mathrm{~dB}$ and more, which was confirmed by the test measurements of TerraSAR-X over tropical rain forest.

\section{B. Theoretical Considerations of Backscattering Due to Hydrometeors}

The radar response (backscattering) from hydrometeors is determined by the raindrop size, shape, density, orientation, and temperature. Furthermore, the backscattering depends on the polarization of the wave interacting with the precipitation media. The theoretical concept that describes the scattering from a dielectric sphere was established by Mie in 1908. The relation to estimate the backscatter cross section of a volume of small particles by assuming the well-known Rayleigh approximation (the diameters $D$ of the raindrops are much smaller than the wavelength $\lambda$ ) is given as

$$
\sigma_{b}=\frac{\pi^{5}}{\lambda^{4}}|K|^{2} \sum_{i=1}^{N} D_{i}^{6}
$$

where

$$
K=\frac{m^{2}-1}{m^{2}+2}
$$

TABLE II

ANNUAL PRoBability For DifFERENT VALUES of RAIN RATE AFTER THE CRANE MOdel

\begin{tabular}{|l|l|l|l|}
\hline Rain rate & \multicolumn{3}{|c|}{ Annual Probability [\%] } \\
\hline$[\mathrm{mm} / \mathrm{hr}]$ & $\begin{array}{l}\text { Southern } \\
\text { Germany }\end{array}$ & $\begin{array}{l}\text { Middle and Northern } \\
\text { Germany }\end{array}$ & $\begin{array}{l}\text { Northern } \\
\text { Brazil }\end{array}$ \\
\hline 2.5 & 0.87 & 0.65 & 3.5 \\
\hline 12.5 & 0.072 & 0.043 & 1 \\
\hline 50 & 0.0049 & 0.0032 & 0.05 \\
\hline 150 & 0.0001 & $2.96 * 10-5$ & 0.02 \\
\hline
\end{tabular}

TABLE III

Annual Probability Values for Different AtTenuation Values After the Crane Model For X-BANd Frequencies

\begin{tabular}{|l|l|l|l|}
\hline Attenuation & \multicolumn{3}{|c|}{ Annual Probability [\%] } \\
\hline \multicolumn{1}{|c|}{$\mathrm{dB}^{2}$} & $\begin{array}{l}\text { Southern } \\
\text { Germany }\end{array}$ & $\begin{array}{l}\text { Middle and Northern } \\
\text { Germany }\end{array}$ & $\begin{array}{l}\text { Northern } \\
\text { Brazil }\end{array}$ \\
\hline 0.1 & 0.43 & 0.32 & 1.69 \\
\hline 0.5 & 0.093 & 0.064 & 0.67 \\
\hline 1 & 0.043 & 0.03 & 0.4 \\
\hline 2 & 0.019 & 0.014 & 0.22 \\
\hline
\end{tabular}

and $m$ is the complex index of refraction of the scattering particle. The summation term for a distribution of particles can be given as

$$
\hat{Z}=\int N\left(D_{e}\right) D_{e}^{6} d D \quad\left[\mathrm{~mm}^{6} \cdot \mathrm{m}^{-3}\right]
$$

where $\hat{Z}$ is termed the reflectivity factor, $D_{e}$ is the diameter of each droplet, and $N\left(D_{e}\right)$ is the number of droplets per unit area. Note that $\hat{Z}$ is commonly given in logarithmic units according to

$$
Z=10 \cdot \log _{10} \hat{Z} \quad[\mathrm{dBZ}] .
$$

The commonly used exponential model of the drop size was found by Marshall and Palmer. This states that the shape of the DSD will vary in response to rainfall intensity such that

$$
\begin{aligned}
N\left(D_{e}\right) & =N_{0} \exp ^{\left(-\lambda_{r} D_{e}\right)} \\
\lambda_{r} & =4.1 R^{-0.21} \mathrm{~mm}^{-1}
\end{aligned}
$$

where $N_{0}$ is a scaling parameter for concentration, with the value of $8000 \mathrm{~m}^{-3} \cdot \mathrm{mm}^{-1}$, and $\lambda_{r}$ is related to the rainfall intensity $R[\mathrm{~mm} / \mathrm{h}]$.

As a practical basis for estimating the precipitation intensity directly from the measured reflectivity factor in still air and vice versa to calculate the reflectivity from the rain intensity $R$, a relation of the form

$$
\hat{Z}=a_{1} \cdot R^{b_{1}}
$$

is used. The parameters $a_{1}$ and $b_{1}$ are dependent on the frequency of the interacting EM waves and on the rain intensity $R$ as well as the DSD. Furthermore, regional-dependent variations due the rain type do exist. A number of $Z-R$ relations were established by many research efforts and are provided, for instance, in [12]. A careful selection of the coefficients has to be performed by considering the appropriate conditions and respective parameters.

The power law in (8) provides an analogy to the calculations of the specific attenuation using (1) given in Section III-A. 


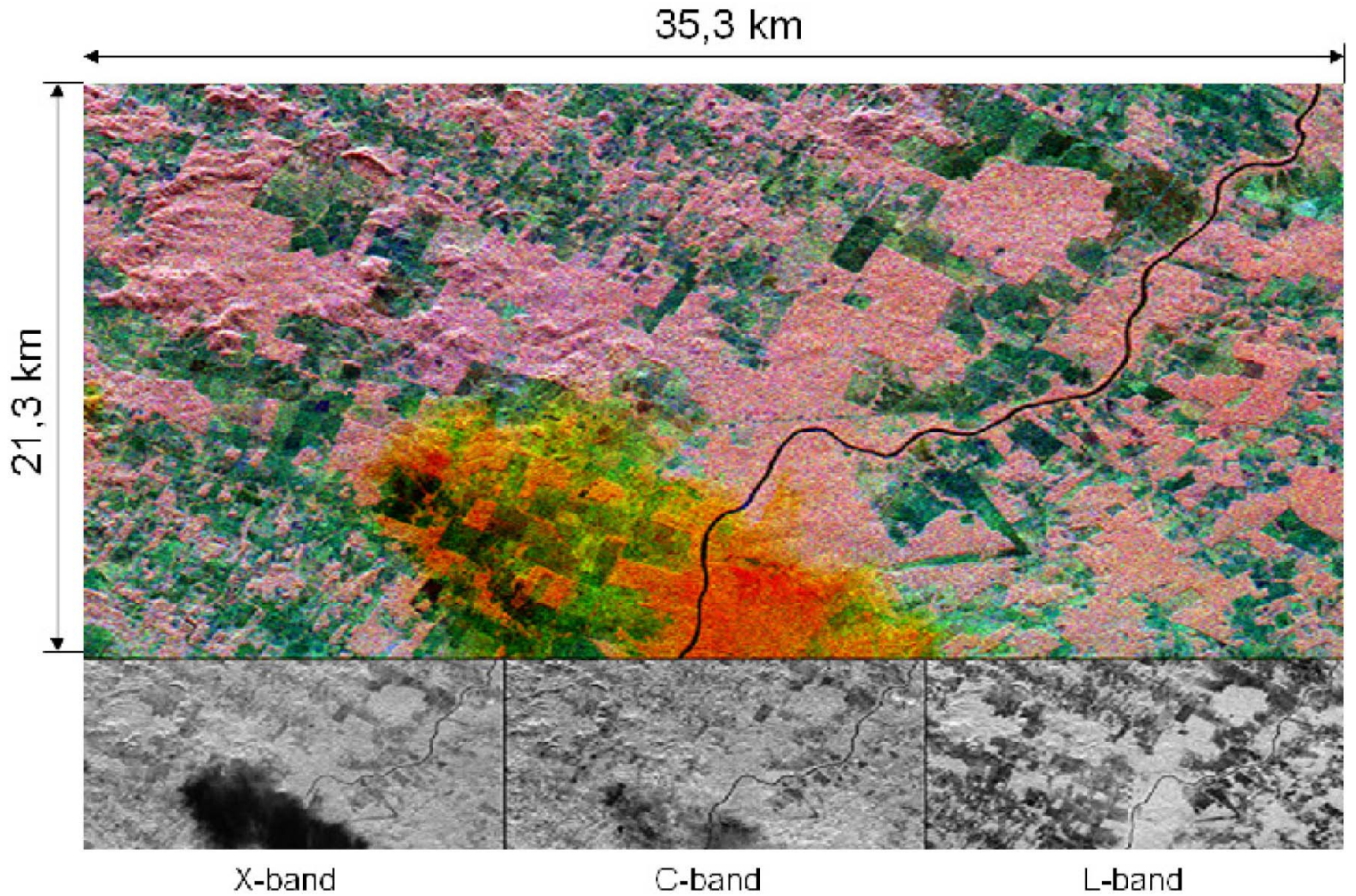

Fig. 2. Example of influence of rain on SAR intensity images, using the RGB composite corresponding to X-band (R), C-band (G), and L-band (B) measurements, respectively. The rain-induced "blocking," as expected, is most pronounced in the X-band case. The images have been recorded during the X-SAR/SIR-C Mission DLR/NASA in 1994. The image is centered at $11.2^{\circ}$ south latitude and $61.7^{\circ}$ west longitude, respectively. North is toward the upper left.

For a further in-depth analysis of the theoretical aspects of backscattering due to hydrometeors, we refer to [11].

For the case of SAR, it can be concluded that the backscattering due to hydrometeors is the minor effect and attenuation due to the precipitation volume is dominating, which is supported by the recent measurements of TerraSAR-X. In Fig. 10 (right-hand side), three regimes in the slant-range reflectivity profile ("A-sope") for the rain-cell cut from a very recent TerraSAR-X measurement over a tropical rain forest in Brazil are provided. The first regime is due to backscattering at the precipitation and about $5 \mathrm{~dB}$ above the backscattering from the unaffected regions of the image. The second regime is because of attenuation due to the precipitation volume. The third one corresponds to nonaffected signals by precipitation. In conclusion, a signal reduction of about $20 \mathrm{~dB}$ between nonaffected and attenuated regions during heavy precipitation is likely for X-band SAR frequencies.

\section{Attenuation and Rain-Rate Statistics}

For the statistical computation, we have used a model provided in [14], which allows the estimation of the annual probability of attenuation as a function of several parameters. These parameters are the signal frequency, the polarization of the signal, the climate zone, the latitude, the station altitude, and the elevation angle. Moreover, it is possible to calculate attenuation for a given annual probability. The model also allows the calculation of the rain rate for a given climatic zone and annual probability. Vice versa, it is possible to estimate the annual probability for a given rain rate. In Table II, we provide example values of the annual probability for different rain rates and different climate zones. The values of the annual probability given in percentage values can be easily transformed into units of days, hours, and minutes per year. As an example, $1 \%$ of the annual probability equals 3.65 days per year. The so-called global attenuation function is used to determine the annual probability of occurrence of attenuation beyond a specified value or to determine the attenuation exceeded with a specified annual probability. Some typical values are given in Table III, and the parameters used in the calculation are $9.6 \mathrm{GHz}$ for the signal frequency, vertical polarization, $45^{\circ}$ for the incident angle, and a station altitude of $0.5 \mathrm{~km}$ above the mean sea level. Comparing some of these values, an attenuation of $1 \mathrm{~dB}$ for a signal with frequency of $9.6 \mathrm{GHz}$ in the tropical area is about ten times more likely than in the region of southern Germany.

\section{Tropospheric Delay Effects}

Tropospheric delay effects are nondispersive for frequencies up to $15 \mathrm{GHz}$. The total delay of signal caused by the troposphere can be subdivided into two parts. The first one is the so-called wet part of the delay, which is strongly affected by variations in the concentration of water vapor. Thus, the temporal variability of water vapor concentration can lead to differences in the propagation delay experienced on different passes in the application of interferometric SAR. The wet delay can reach typical values up to $0.4 \mathrm{~m}$. The second part is the so-called dry part of the delay. Dry delay effects occur due to the gaseous nature of the lower part of the atmosphere and are 


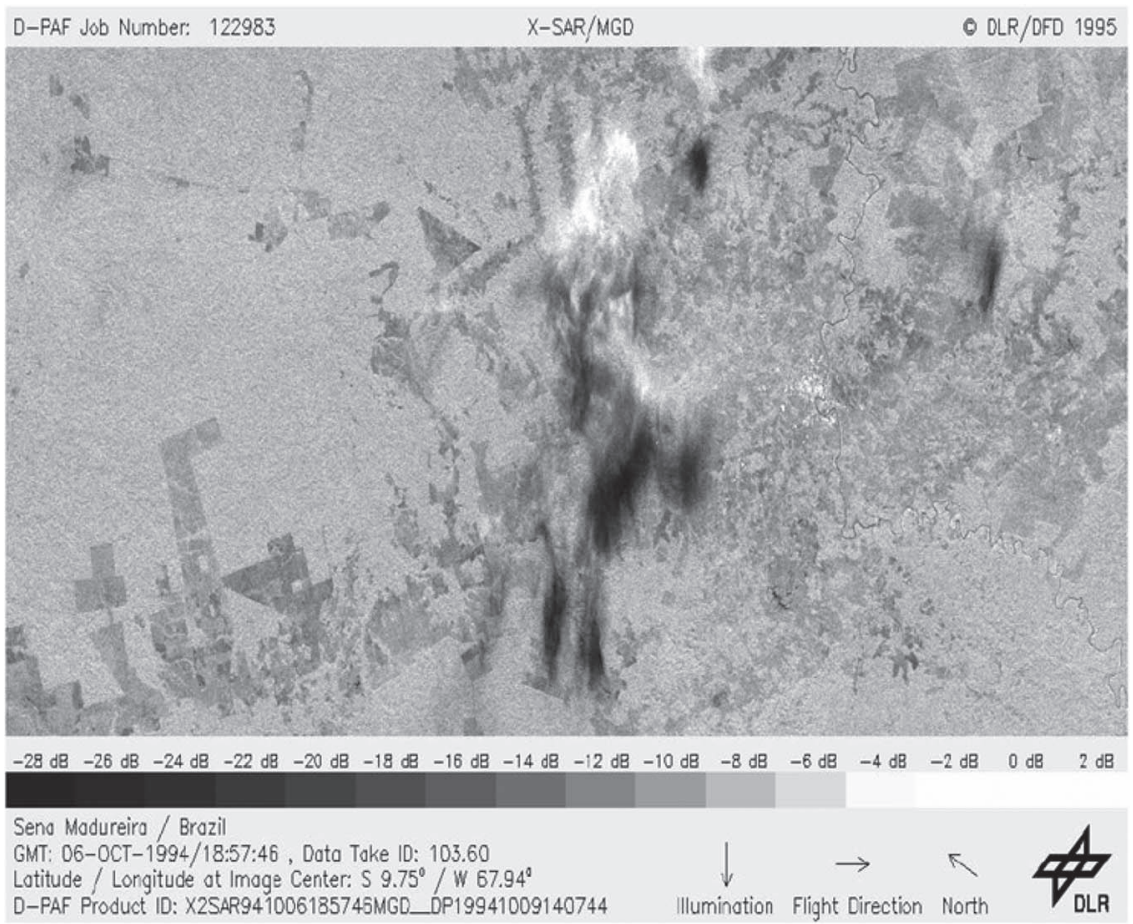

\section{X-SAR/SIR-C Mission, DLR/NASA, 1994}

Fig. 3. Example of rain-cell-affected SAR signatures recorded during the SIR C/X mission. The white area is due to direct reflections from the rain region, whereas the darkly shaded areas are due to rain-attenuated (blocked) signals from the ground.

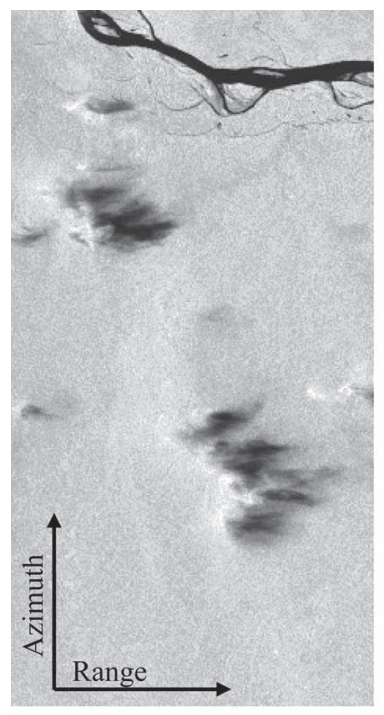

(a)

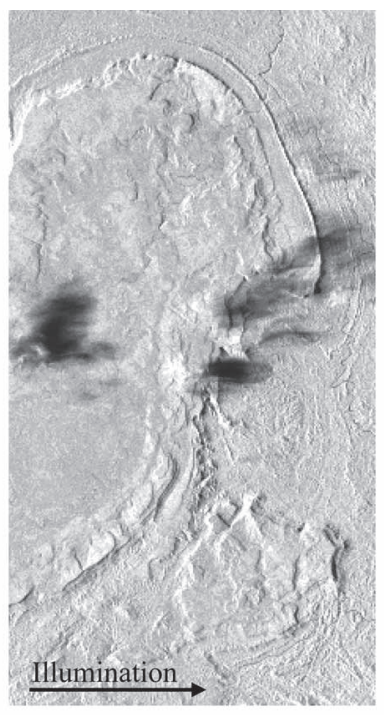

(b)

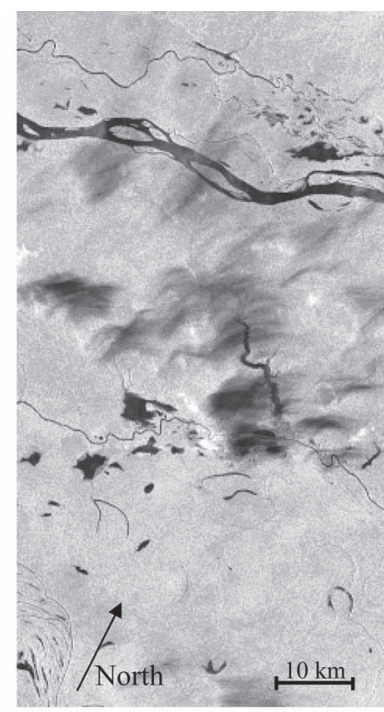

(c)

Fig. 4. Further examples of weather-corrupted SAR images, SRTM mission (X-band: $9 \mathrm{GHz})$ from the Brazilian rain forest. The horizontal corresponds to range, and the vertical to the azimuth direction. The direction of illumination for all three images is given from the left- to the right-hand side. (a) DT: 087.070 Scene: 740. (b) DT: 150.050 Scene: 820. (c) DT: 039.070 Scene: 740.

less variable than the wet component, although the absolute range delay can reach values up to $2.3 \mathrm{~m}$. However, they can be well modeled using the atmospheric parameter temperature, humidity, and air pressure at the surface, and the resulting error in the zenith path may be corrected to an accuracy of $1 \mathrm{~mm}$. GPS measurements are being used to estimate the wet delay by subtracting the modeled dry delay from the total delay. However, the limited number of ground receivers requires some form of interpolation.

\section{Assessment and Management of Propagation EFFECTS IN SAR MEASUREMENTS}

\section{A. Examples of How the Troposphere Affects Multimodal SAR Applications}

In this section, examples are provided about how the atmosphere is affecting multimodal spaceborne SAR sensors The chosen data sets emphasize distortions due to the atmospheric (tropospheric) effects. The selection of such data 


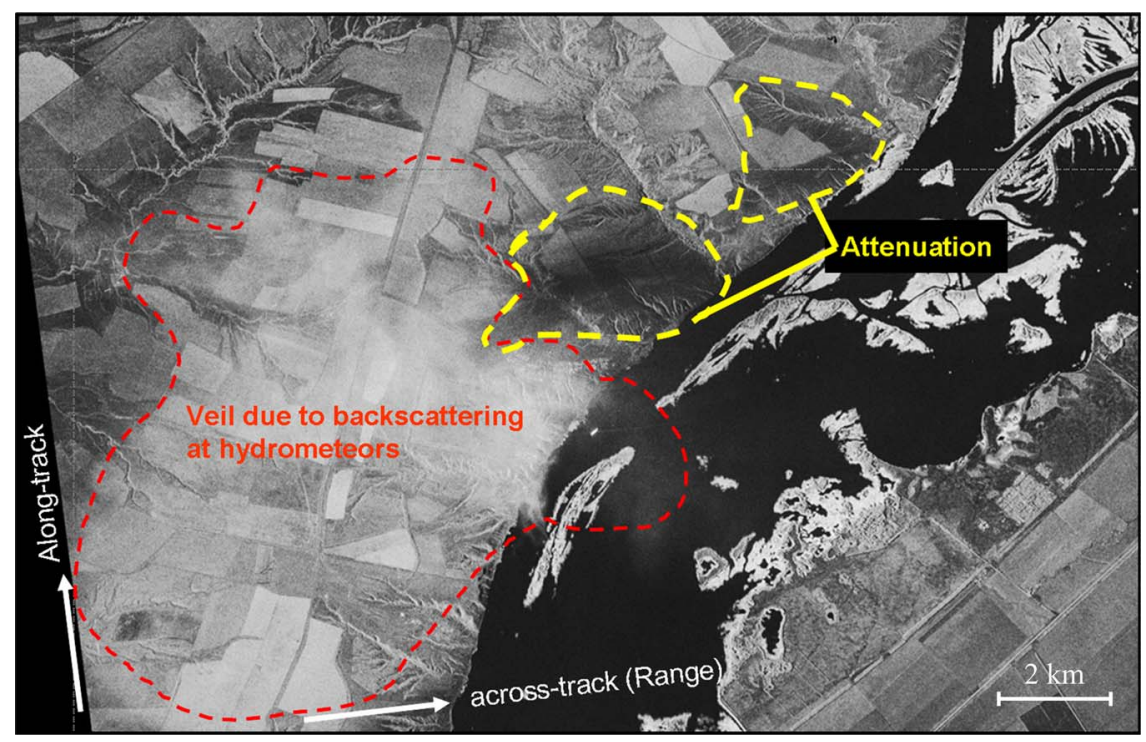

Fig. 5. Example of rain-cell-affected SAR signatures recorded with TerraSAR-X from the first data take (image) over Volgograd region, Russia, on June 19, 2007. Again, the white shading is due to direct reflections from the rain region (shown as volume "A" in Fig. 9), whereas the darkly shaded areas are due to rainattenuated (blocked) signals from the ground; this effect is shown as region "B" in Fig. 9. The parameters of acquisition are given in Table II. The corresponding information about the weather conditions at the acquisition were obtained from the regional weather service: http://meteo.infospace.ru. The prevailing cloudiness was $80 \%$, the cloud base around $800 \mathrm{~m}$ and thunderstorms-with-rain conditions were confirmed.

represents a major effort in obtaining scientific information. Huge volumes of data were carefully inspected in order to obtain the desired subset of measurements.

The area shown in Fig. 2 is in the state of Rhodonia in western Brazil. The pink areas are pristine tropical rain forests, and the blue and green patches are areas where the forest has been cleared for agriculture. The image was acquired by the spaceborne imaging radar "SIR-C/X-SAR" on April 10, 1994 onboard the space shuttle Endeavour. SIR-C/X-SAR was a joint mission of the German, Italian, and the United States space agencies. The multifrequency space radar image of a tropical rain forest in western Brazil shows rapidly changing land use patterns, and it also demonstrates the capability of the different radar frequencies to detect and penetrate heavy rainstorms. The RGB composite image was created by combining three radar measurements in three different frequency bands. The lower left image, X-band vertically transmitted and received, is red in the color image; the lower center image, C-band horizontally transmitted and vertically received, is green; and the L-band image is depicted in blue. A heavy downpour in the lower center of the image appears as a black "cloud" in the X-band image, with the same area showing up faintly in the C-band image, and is practically invisible in the L-band image. When combined in the color image, the rain cell appears red and yellow. Although radar can usually "see" through clouds, at short radar wavelengths, it can be affected by unusually heavy rainfall cells. L-band, at $21-\mathrm{cm}$ wavelength, is unaffected by such rain cells. By analyzing the way the radar image changes under the influence of weather, it may be possible to estimate rainfall rates. Another example for the influence of rain on SAR images is shown in Fig. 3, where comparable effects to Fig. 2 (X-band frequencies) may be observed.

Before we discuss the underlying physics in more detail, further examples of corrupted SAR data by heavy rain are shown in Fig. 4(a)-(c). The three data sets are showing affected data from the SRTM which aimed at generating a digital eleva-

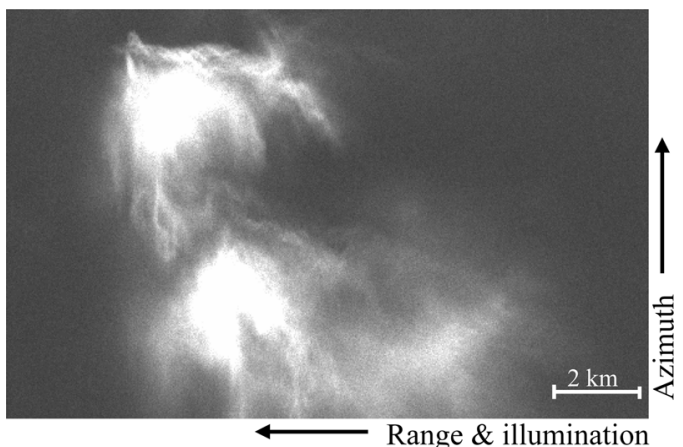

Fig. 6. Cutout of a TerraSAR-X image over the sea surface near Borneo demonstrating strong precipitation reflection over water. Such measurements have a great potential in quantifying precipitation over oceanic surfaces, a problem hitherto only poorly addressed. In effect, the disadvantage of rain features in SAR imagery may turn out to be a useful source for assessing precipitation intensity over SAR-imaged areas.

tion model (DEM) for the globe from $57^{\circ}$ north to $57^{\circ}$ south. The imaging SAR was also operating in the X-band frequency range, and all of the three images were acquired from the rain-forest area over Brazil, where heavy precipitation events occur with a higher likelihood compared to temperate zones. For a comparison of the rain-rate statistics and attenuation statistics, cf. Tables II and III.

\section{Precipitation Effects in TerraSAR-X Images}

The German Earth-observing SAR satellite TerraSAR-X [19] was launched on June 15, 2007. Some appropriate data takes are presented here, which have been selected because they are interesting in terms of propagation effects. Examples are shown in Figs. 5-8, 10, and 11, respectively. For Fig. 5, some of the image acquisition parameters can be found in Table IV. However, the image presented is extracted from the full scene, and the reduced dimensions are approximately $20 \times 15 \mathrm{~km}$. Range 

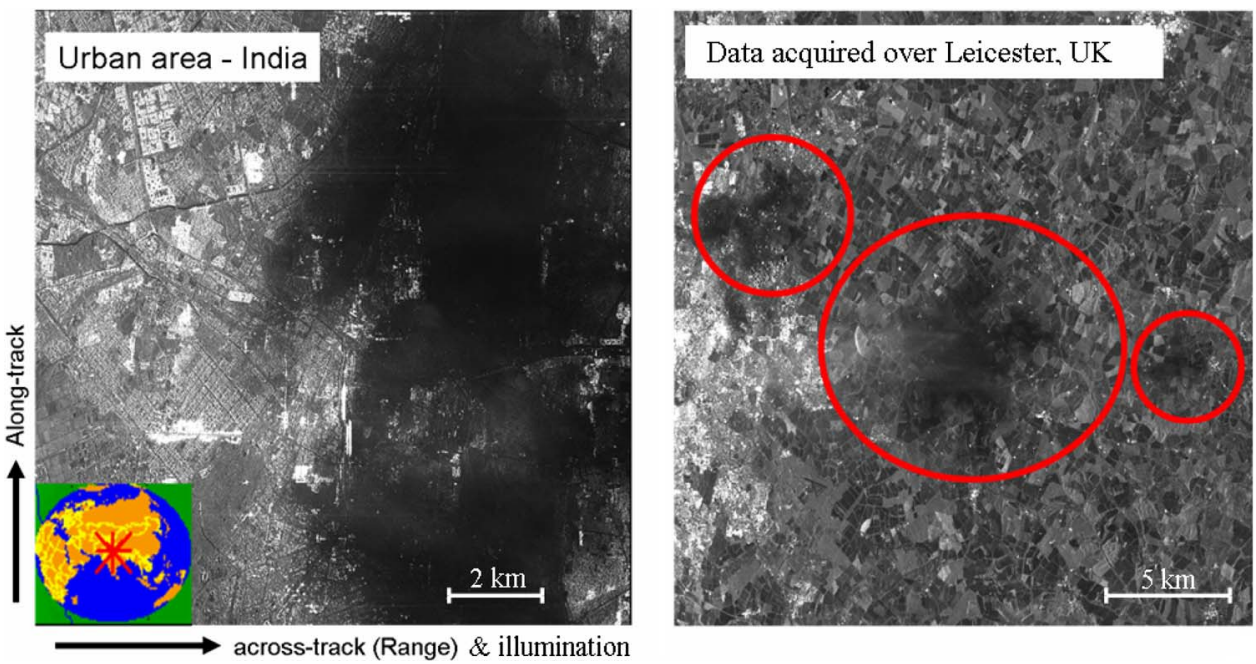

Fig. 7. (Left) TerraSAR-X image acquired from an urban area in central India. This is a rather rare example of acquisition, where almost half of the city is covered by a heavy downpour. Out of the subset of 12000 scenes, which has been investigated, only two such cases have been observed. (Right) Example of several artifacts (dark spots) in a TerraSAR-X image near Sheffield, U.K., provides an example of how rain can also affect measurements in the European climatic zone. This observation confirms that SAR imagery in the northern latitudes is also vulnerable to precipitation-induced distortions.

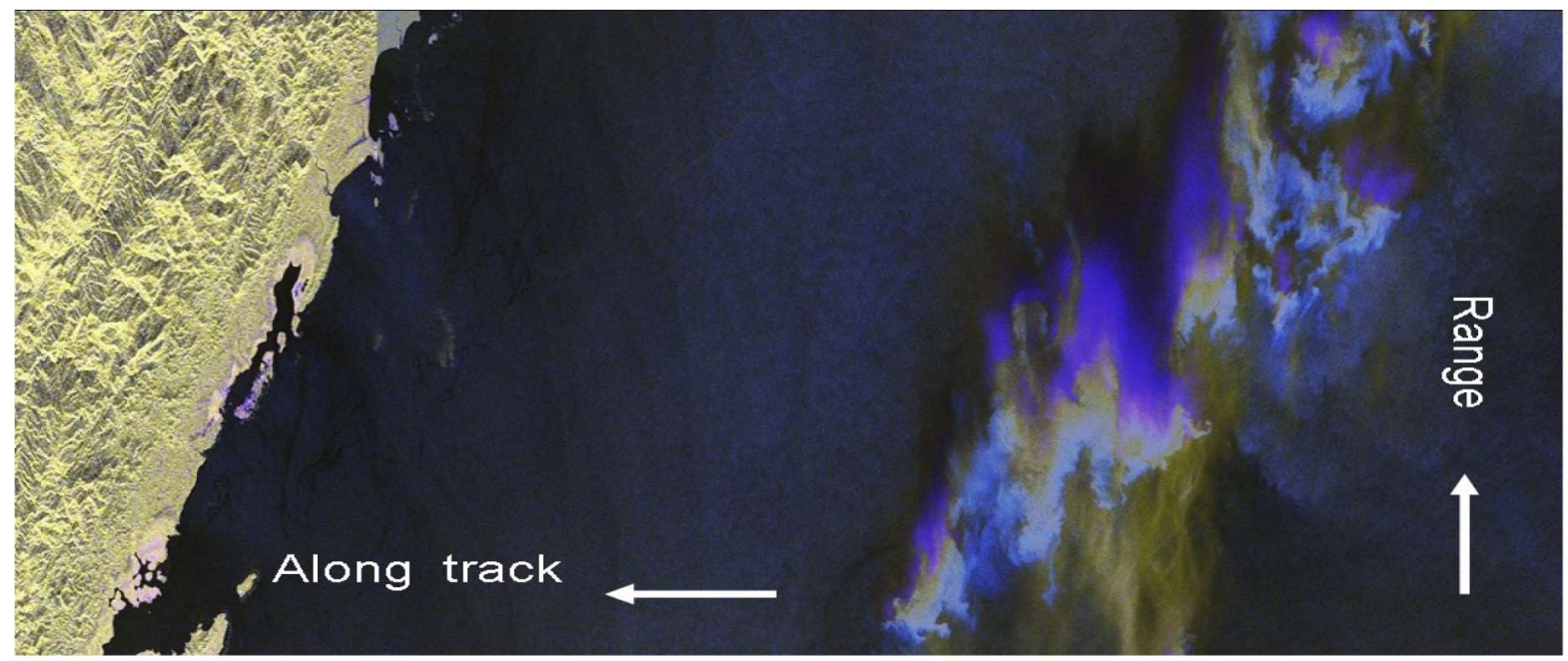

Fig. 8. Color composite HH/HH-VV/VV polarimetric image acquired by TerraSAR-X in strip-map mode over ocean surface close to the coast of Panama (Scene Center: Lat.: $-5.5^{\circ}$, Long.: $-62^{\circ}$ ). The image dimensions in range and azimuth are 30 and $60 \mathrm{~km}$, respectively. The direction of illumination is according to the arrow given for the range direction in a descending orbit. The color coding is given as follows: (HH) red, (HH-VV) blue, and (VV) green. The blue-colored zones correspond to regions, where the precipitation leads to pronounced differences in $\mathrm{HH}$ and VV signal intensity.

and azimuth correspond to the horizontal and vertical directions, respectively. During this survey, a thick cloud cover of about $80 \%$ prevailed, and according to the regional weather service, thunderstorms and heavy rain showers took place during the image acquisition. As shown earlier, for shorter wavelengths, exceptionally strong precipitation events like heavy thunderstorms may influence even radar imaging at C-band (approximately 5-cm wavelength). Such an event can be seen in the left part of the radar image as a bright "veil" and in the righthand side as an accompanying dark patch. The dimension of the artifact covers an area of about $10 \times 10 \mathrm{~km}$. Figs. 3 and 4 show similar effects comparable to Fig. 5; however, the reflections from the precipitation media are less pronounced. The dark patch in the center of the image can be related to the strong attenuation by the precipitating media. Fig. 10 shows a classical example that is similar to those of Figs. 2 and 4(a)-(c). Such an example may be used to determine the backscatter coefficient for distributed targets, since the rain forest is well suited to serve as a homogenous scatterer. Therefore, the in-orbit antenna pattern verification is also partly performed over a homogenous rain forest. The backscatter coefficients of affected and nonaffected regions have been calculated for the given scene, and the differences reach values up to $15 \mathrm{~dB}$. An interesting example is shown in Fig. 6, which is taken over a water surface close to Borneo which also belongs to the tropical climate zone with an increased likelihood for heavy rain. The bright patterns are due to regions of heavily precipitating volumes, which are due to strongly reflected SAR signals. The accompanying dark spot due to attenuation cannot be discriminated from the faintly reflecting water surfaces. 


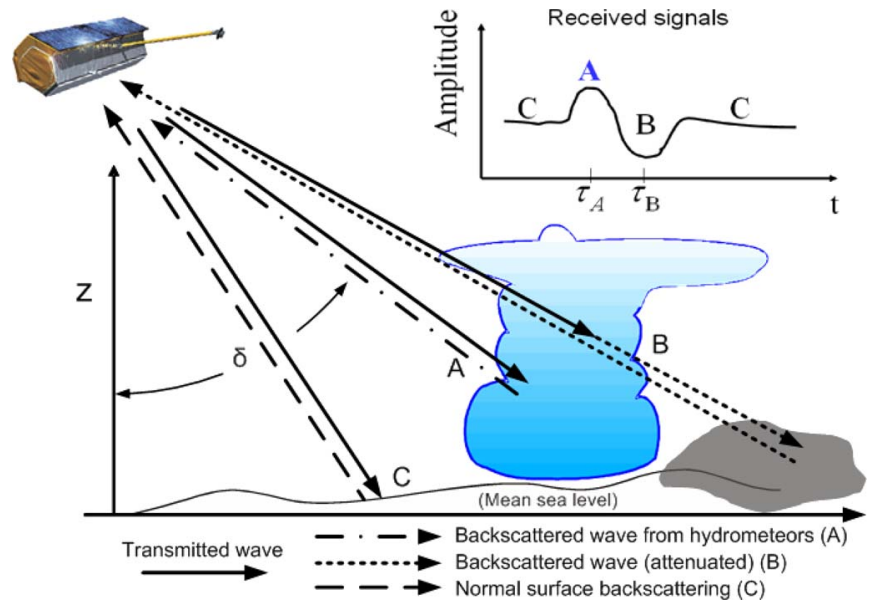

Fig. 9. Physical interpretation of rain-cell signatures in SAR images, as indicated and introduced previously in Fig. 3 (adopted from the study of Runge et al. [20]).

\section{A. Physical Interpretation of Artifacts in SAR Images Due to Precipitation}

A physical interpretation of how rain cells affect SAR images is shown in Fig. 9 (adopted from the study of Runge et al. [20]). The image shows an imaging scenario, where the transmitted waves interact with a precipitation cell. It can be observed that area "A," which corresponds to time instant $\tau_{A}$ in the amplitude/time diagram, is due to strong backscattering from large hydrometeors. Time instant $\tau_{B}$, which corresponds to the region "B," proves that signals have been heavily attenuated. By comparing the encircled areas in Fig. 5 and the amplitude/time diagram in Fig. 9, the veil in Fig. 5 corresponds to area "A" $\left(\tau_{A}\right)$, and the shadowlike black areas close to this veil in Fig. 5 correspond to the region "B" $\left(\tau_{B}\right)$ in Fig. 9. These physical processes are elucidated with the help of Fig. 10 where a SAR-amplitude cutout of a cross-track profile through a rain cell is depicted. As diagrammatically shown, the backscattering is accompanied with higher amplitude values, and the weak signals behind the first maxima belong to the black shadows behind the right-hand side of the bright spots, where up to 30-dB difference in decibel level may be observed. These findings agree with attenuation analysis reported in [21] with $\mathrm{X}$-band weather-radar measurements.

\section{B. Test Case and Comparison of SAR Data With Simultaneously Measured Ground-Based Weather-Radar Data}

Fig. 11 shows a comparison of two different types of images measured almost at the same time, where the image on the righthand side was acquired with TerraSAR-X strip-map mode in ascending orbit over New York.

The image on the right-hand side displays the corresponding weather-radar image measured by a ground-based weather radar (WSR-88D) located in New York (Nexrad code: KOKX). The data were obtained using the freely available Java NEXRAD viewer provided by the National Oceanic and Atmospheric Administration, U.S.

A good agreement between visible artifacts shown in the SAR image (some of them encircled in red color) and the reflectivity plot on the right-hand side was observed. Such reflectivity maps display the echo intensity of the transmitted radar signals and are shown in dBZ. These maps are used to detect precipitation and evaluate storm structures. It is the best available means to compare precipitation volumes and precipitation-induced signatures in SAR images. The reason lies in the high achievable spatial resolution and the possibility to measure at almost the same instant of time. The red regions in the weather-radar image correspond to reflectivities up to 50, in some cases $55 \mathrm{dBZ}$, which corresponds to high precipitation intensities typically occurring during thunderstorms.

The comparison of ground-based weather-radar and SAR data will be certainly useful in the process to derive rainintensity information from SAR-based measurements which will be discussed in some detail in the following section.

\section{Rain-Intensity Estimation Using SAR Measurements}

Efforts to derive the rain-intensity information from SAR measurements have been made several times and have been reported for example in [22]-[27]. However, the material will not be repeated here given in these references.

In this paper, we provide some basic considerations, why such measurements would be useful, what are the major challenges, and a detailed application to TerraSAR-X data is left of future studies.

Particularly for remote regions out of reach by groundbased weather-radar measurements, SAR-based observations may add value as an input parameter for climate models. However, there are several limitation and challenges which have to be faced in order to retrieve meaningful precipitation intensity information. First, all the single hydrometeors are nonstationary targets and are decorrelating because hydrometeors (drops, hailstones, snowflakes, graupel, etc.) are in relative motion. Note that the decorrelation time for droplets is around $10 \mathrm{~ms}$ for $\mathrm{C}$-band frequencies. Thus, this relative motion may cause the ground image to be unfocused and partly exhibit a smeared appearance. In addition, the entire precipitation medium may be laterally in relative motion to the ground and therefore displaced like a ground moving target due to its Doppler shift. Assuming the case where the rain rate cannot be retrieved with high precision, the image is not completely focused, and some areas are depicted displaced, it may be possible to retrieve some meaningful structural information. That is, we could use ground image distortions to deduce information concerning the precipitation layer causing the very distortions, causing the propagation-induced defocusing. This becomes evident by comparing the resolution of other spaceborne sensors, like the tropical rainfall measurement mission with a spatial resolution of $4 \times 4 \mathrm{~km}^{2}$ [28]. As a preliminary conclusion, meteorological information retrieved using SAR measurements may bear useful information, not on its own but when combined with other sensors as a supplementary source of information.

\section{INFLUENCE OF TROPOSPHERIC PROPAGATION EFFECTS ON THE CALIBRATION OF TerraSAR-X}

The influence of atmospheric effects on the XCAL of SAR systems like TerraSAR-X $(9.65 \mathrm{GHz})$ does, under certain circumstances, exceed the instrumental errors. Therefore, there is a demand to detect and monitor extraordinary precipitation events which might occur during the data acquisition. In 


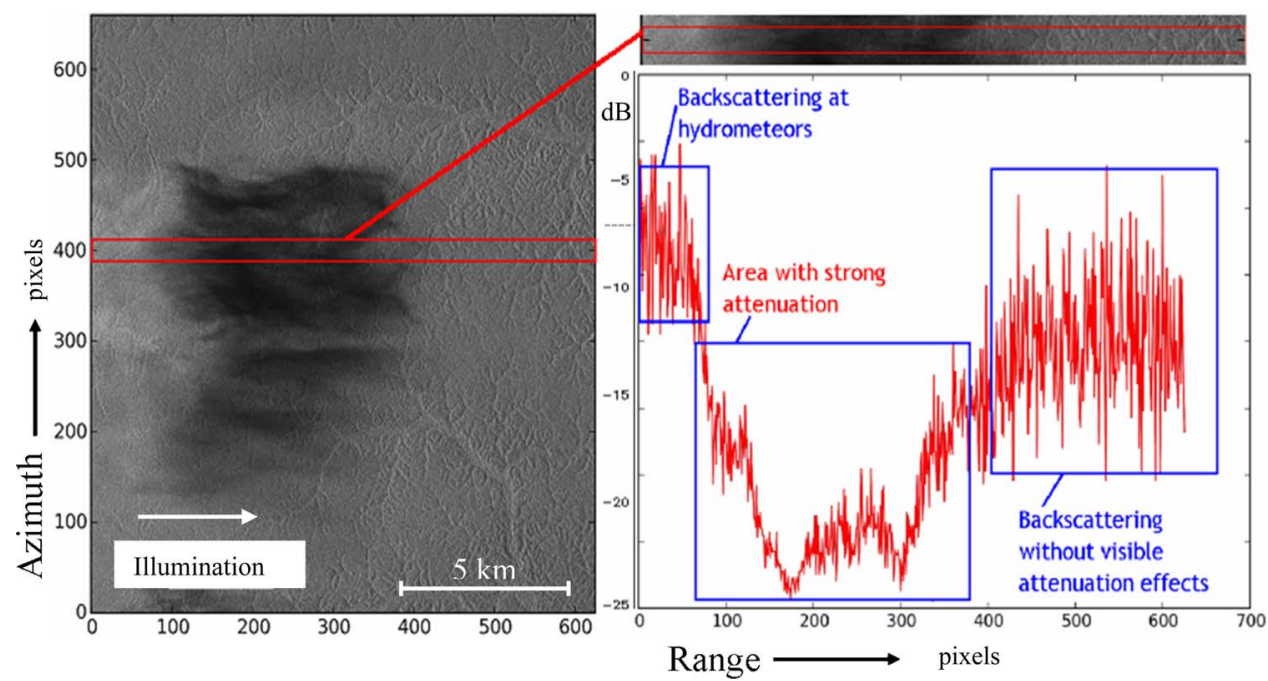

Fig. 10. Depiction of a slant-range reflectivity profile ("A-sope") for the rain-cell cut from a very recent TerraSAR-X measurement over a tropical rain forest in Brazil. Such data sets may, at some stage, enable estimation of rain rate over such isolated areas. This figure was inspired by the study of Runge et al. [20] who analyzed reflectivity profiles of SRTM data takes over a tropical rain forest.

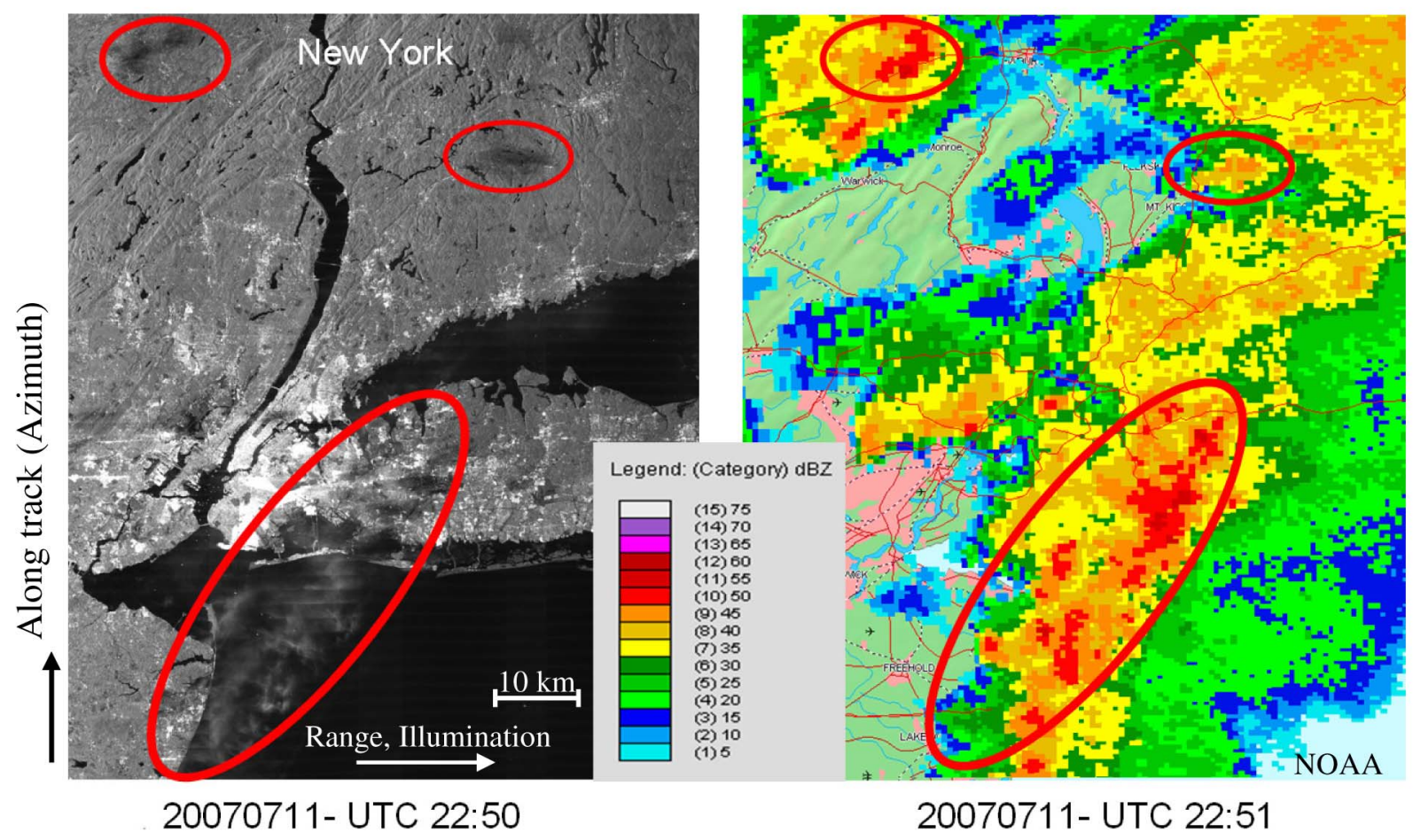

Fig. 11. Test case showing a comparison of TerraSAR-X and weather-radar data acquired nearly simultaneously (within the same minute) over New York, U.S. A good agreement between the rain-cell signatures in (left) the SAR image and (right) the weather-radar image can be observed. The effects are most pronounced for reflectivities of up to $50 \mathrm{dBZ}$. The SAR image was acquired in ascending orbit direction, and the range direction corresponds with the horizontal. The look direction was from left to right. The vertical corresponds to the along-track direction. Image dimensions are approximately $130 \mathrm{~km}$ in azimuth and $100 \mathrm{~km}$ in range direction.

general, the estimation of the path attenuation will be of limited accuracy and contain an unremovable uncertainty. The main limitation is the resolution of the available weather data, which allows not only for retrieving the path attenuation between the sensor and the calibration targets but also for determining phase and polarization changes. Furthermore, an insurmountable problem arises due to the fact that, for each calibration target, an individual radar range-height-indicator (RHI) scan would be required and would have to be collected nearly simultaneously. In conclusion, there are two main problems in correcting for the attenuation due to heavy rain.

1) The limited accuracy of the recorded rain-rate data.

2) There are practical constraints in collecting the data, since for every XCAL target, an individual RHI scan would be required, which is not feasible due the limited acquisition capability of a weather radar, i.e., it is not possible to acquire data for several different scatterer ensembles nearly simultaneously within a reasonable acquisition time. 
TABLE IV

MaIn ACQuisition Parameters of the First Image ACQUiRed BY TerraSAR-X OBTAINED 4.5 DAYS AFTER LAUNCH

\begin{tabular}{|l|l|}
\hline Parameter & Values \\
\hline Date & 20070619 \\
\hline Time & $15: 03: 24-15: 03: 31: 07$ \\
\hline Frequency band & X-band / 9.65 GHz \\
\hline Image dimensions & Azimuth: $\sim 30 \mathrm{~km}$ Range: $\sim 30 \mathrm{~km}$ \\
\hline Location & $50 \mathrm{~km}$ to the west of Volgograd (Russia) \\
\hline Scene center & Lat: 48.4504 Lon: 43.5542 \\
\hline Polarization & HH \\
\hline Imaging Mode & Strip map \\
\hline Look direction & right \\
\hline Orbit direction & Ascending \\
\hline
\end{tabular}

However, being able to detect high rain rates, at least, and subsequently to flag affected SAR data products, the calibration acquisitions should be monitored. Thus, flagged SAR data products can be excluded from the XCAL procedure.

\section{A. Monitoring of the TerraSAR-X Test Site During the XCAL Campaign}

The objective to monitor the test site during the XCAL campaign is the detection of heavy precipitation events ( $>14 \mathrm{~mm} / \mathrm{h}$ ). Therefore, the weather-radar data from the weather service can be utilized, which provide an update of plan position indicators every $15 \mathrm{~min}$ for the test-site area.

Suggestion Toward XCAL Strategy Regarding Atmospheric Effects: The previous sections dealt with the problem of propagation effects related to the XCAL of spaceborne SAR system in general. Attenuation and possible phase changes due to heavy rain events have been identified as the main reason for propagation effects at X-band. Such events do comprise convective precipitation cells typically existent during thunderstorms. The detection of such events can be performed using weather-radar measurements. There are two different sources to estimate the rain rate: the weather-radar data, e.g., from the German weather service DWD and the DLR-polarization diversity radar (POLDIRAD). The analysis of both types of data has shown good agreement as reported in [29]. Furthermore, the analysis showed that the accuracy of the data is not sufficient in terms of a deterministic correction approach in the magnitude of tenths of decibels. The way to tackle the problem of tropospheric propagation effects due to rain is done as follows: Heavy precipitation events $(\sim 14 \mathrm{~mm} / \mathrm{h})$ occurring approximately less than $6 \mathrm{~h}$ per year will be observed and filtered using the collected weather-radar data from the regional weather service, which allows for estimation of the rain rate at the calibration test site in, for example, southern Germany (Bavaria). In addition, the in situ observation of the calibration team will be taken into account to support the decision. As the correction of the attenuation in the magnitude of tenths of decibels is not easily implementable, affected data sets will be flagged and excluded from the XCAL, i.e., from the procedure, to derive the absolute calibration factor [29]-[31]. For the case of TerraSAR-X, the simultaneously acquired weather-radar measurements for each data take of TerraSAR-X have been analyzed (see Fig. 12). The total number of analyzed scenes was 168 , where 141 measurements were acquired without any precipitation. From the remaining 27 scenes with rain, four measurements could be identified with

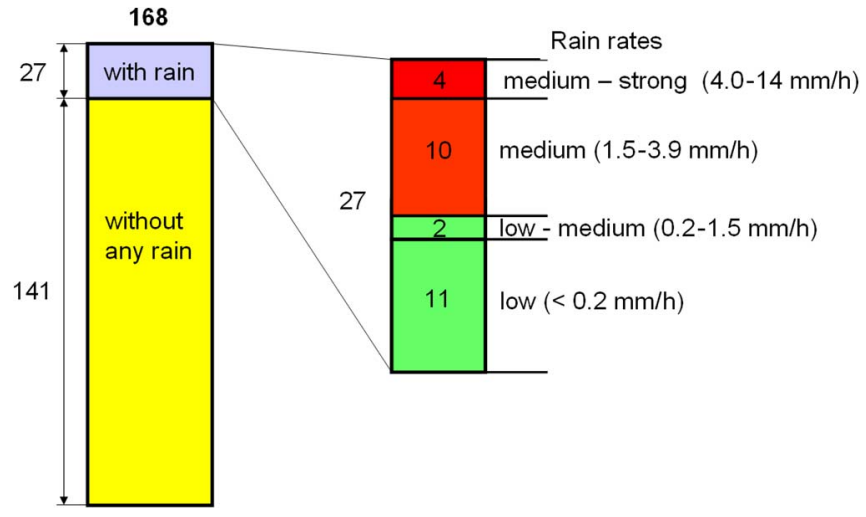

Fig. 12. Illustrative depiction of the weather conditions during the acquisition of the calibration data takes over the test site in southern Bavaria. The rain information was extracted automatically from a ground-based weather-radar network with an update interval of precipitation information of $15 \mathrm{~min}$. The total number of acquired scenes during the XCAL was 168, where 27 of those scenes were acquired during rainy conditions. Four data takes were flagged and excluded from the procedure to derive the absolute calibration constant, thus allowing an improvement of the absolute calibration factor by $0.15 \mathrm{~dB}$.

strong rain, and they have been, in turn, excluded from the procedure to derive the averaged absolute calibration constant. Thus, the overall uncertainty of the absolute calibration factor was reduced by $0.15 \mathrm{~dB}$ (1-sigma) (Figs. 13 and 14).

\section{CONCLUSION AND OUTLOOK}

The conclusions in this paper are manifold. First of all, propagation effects can be very important, and they need to be considered in interpreting radar images. Attenuation caused by heavy rain events has been identified as the main potential reason for atmospheric image degradation and artifacts. The underlying analysis comprised more than 12000 TerraSAR-X data takes. A maximal attenuation up to $30 \mathrm{~dB}$ through the precipitation volumes may occur in the cases of heavy precipitation, for instance, when data takes are acquired over the Brazilian rain forest.

Clouds with low liquid-water content or low rain rates and homogenous distribution cause no or negligible distortions (visible artifacts). The highly flexible TerraSAR-X instrument offers new possibilities for investigation of propagation effects in SAR imaging, and the results presented may be also important for future systems operating with higher nominal frequencies, e.g., the Ku-band or Ka-bands where propagation effects due to precipitation will become even more severe. For such cases, the results presented in this paper may act as a useful reference. In a test case, it was shown, for the first time, that simultaneous precipitation measurements with weather radars are in good agreement with the rain-cell signature observed in the TerraSAR-X images and that such simultaneous measurements are now available for further in-depth study of attenuation effects and are an invaluable source of information for further investigations of attenuation effects and their quantification.

For the XCAL of a spaceborne SAR system, it was shown that the inclusion of precipitation information data acquired by ground-based weather radars improved the accuracy of the absolute calibration factor by $0.15 \mathrm{~dB}$. By considering the finally achieved absolute radiometric accuracy for TerraSAR-X, i.e., $0.31 \mathrm{~dB}$ (1-sigma), this is, in turn, a remarkable contribution. 


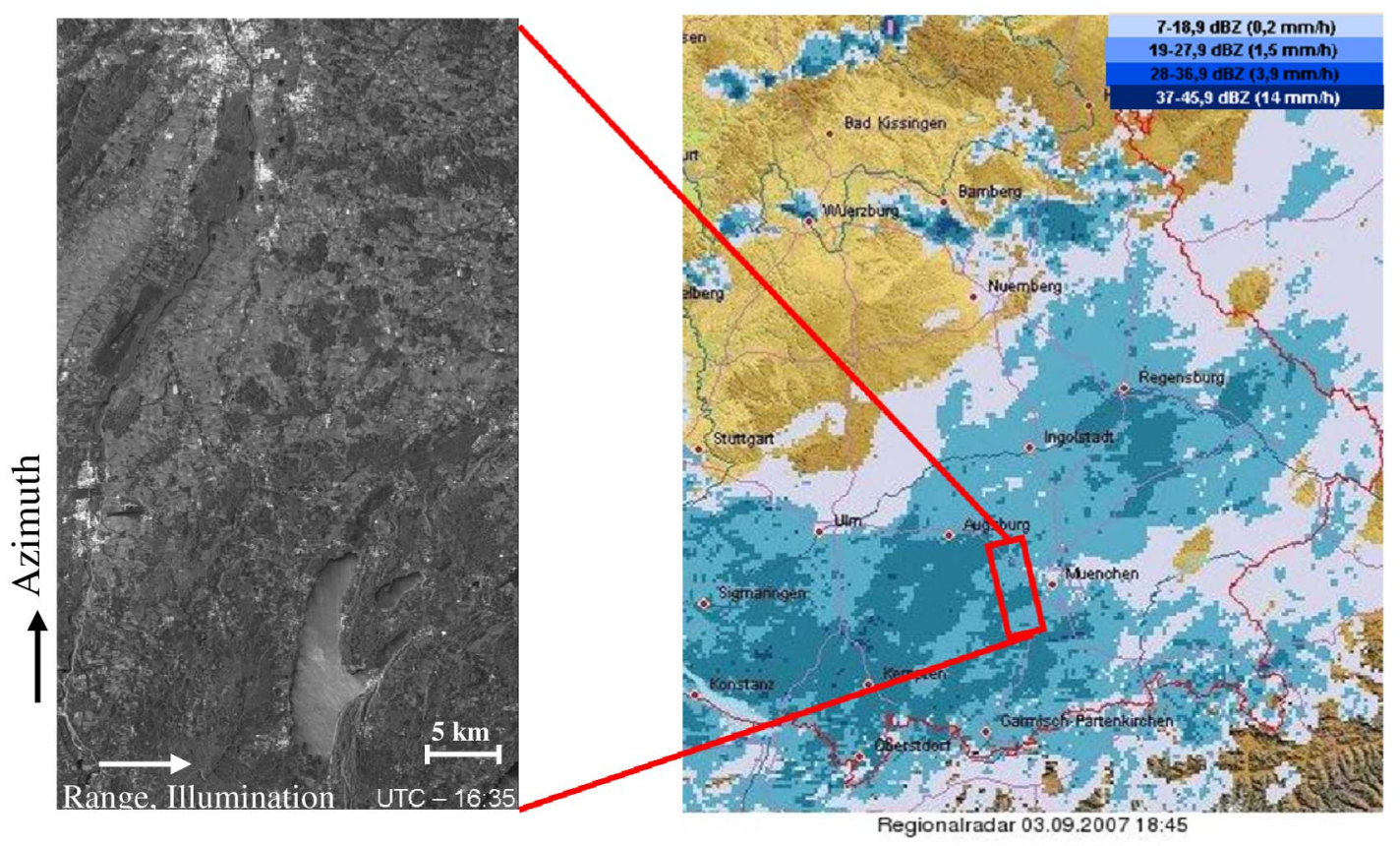

Fig. 13. (Left) TerraSAR-X image acquired over southern Bavaria to the west of Munich. No visible rain-induced signatures could be observed. However, several measurement outliers were identified during the point target analysis applied for the XCAL. Consequently, the (right) respective weather-radar image was consulted to explain the reduction of the backscatter cross section. In turn, the precipitation volume prevailing during the acquisition was the reason for a reduced backscatter cross section. The rain type was stratiform, i.e., with a homogenous distribution. In Fig. 14, the median values for the absolute calibration factor given in decibels of the scene with and without precipitation volume are compared. A difference of $0.57 \mathrm{~dB}$ has been observed. Thus, it was possible to prove signal weakening due to stratiform precipitation without identification of any visible effects in the SAR image itself.

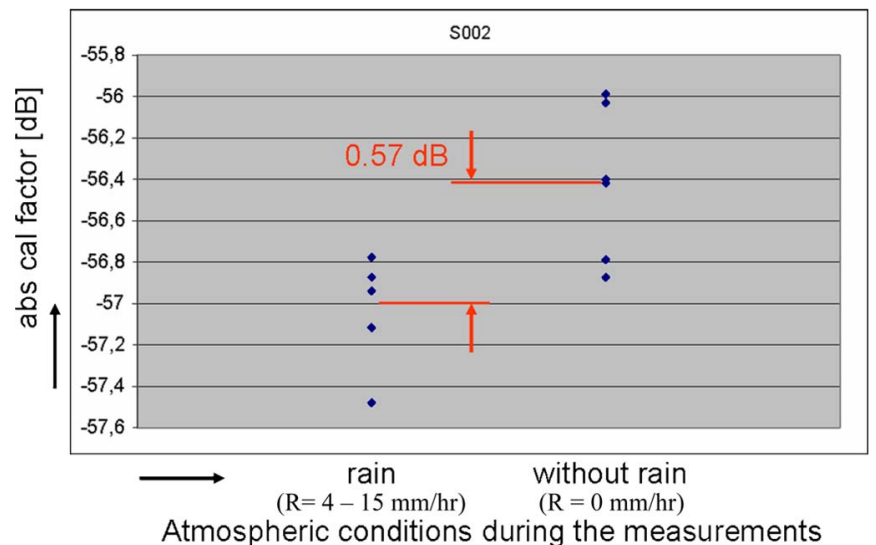

Fig. 14. Diagram shows the difference in the absolute calibration factor for measurements taken at different atmospheric condition. The red lines indicate the location of the median value of measurements of the passive targets (corner reflectors). A difference of $0.57 \mathrm{~dB}$ has been observed for measurements during rain conditions and conditions without any rain.

\section{ACKNOWLEDGMENT}

The work of the reviewers, who provided constructive comments and criticism, is kindly acknowledged. A. Danklmayer would also like to thank the director of the Microwaves and Radar Institute, Prof. A. Moreira, and Dr. G. Krieger for making this paper possible as well as S. Suchandt from DLR-IMF for discussion and interactions on the subject-matter. Also, sincere thanks to Prof. emeritus W.-M. Boerner for his interest in our work, his support, and friendship during the past years.

\section{REFERENCES}

[1] R. L. Jordan, B. L. Huneycutt, and M. Werner, "The SIR-C/X-SAR synthetic aperture radar system," Proc. IEEE, vol. 79, no. 6, pp. 827-838, Jun. 1991

[2] M. Werner, "Shuttle Radar Topography Mission (SRTM): Mission overview," J. Telecommun. (Frequenz), vol. 55, pp. 75-79, 2001.

[3] J. M. Rignot, "Effects of Faraday rotation on L-band interferometric and polarimetric synthetic aperture radar data," IEEE Trans. Geosci. Remote Sens., vol. 38, no. 1, pp. 383-390, Jan. 2000.

[4] S. Quegan and J. Lamont, "Ionospheric and tropospheric effects on synthetic aperture radar performance," Int. J. Remote Sens., vol. 7, no. 4, pp. 525-539, Apr. 1986.

[5] Z. W. Xu, J. Wu, and Z. S. Wu, "A survey of ionospheric effects on spacebasedradar," Waves Random Media, vol. 14, no. 2, pp. 189-273, Apr. 2004

[6] F. J. Meyer and J. B. Nicoll, "Prediction, detection, and correction of faraday rotation in full-polarimetric L-band SAR data," IEEE Trans. Geosci. Remote Sens., vol. 46, no. 10, pp. 3076-3086, Oct. 2008.

[7] K. Davies, Ionospheric Radio, ser. Number 31 in IEE Electromagnetic Waves Series. Stevenage, U.K.: Peregrinus, 1990.

[8] Specific Attenuation Model for Rain for Use in Prediction Methods, 2005 ITU-Recommendation P. 838-3.

[9] M. P. Hall, Effects of the Troposphere on Radio Communication. Stevenage, U.K.: IET, 1979

[10] A. W. Doerry, "Atmospheric loss considerations for synthetic aperture radar design and operation," Proc. SPIE, vol. 5410, pp. 17-27, 2004.

[11] T. Oguchi, "Electromagnetic wave propagation and scattering in rain and other hydrometeors," Proc. IEEE, vol. 71, no. 9, pp. 1029-1078, Sep. 1983.

[12] L. J. Battan, Radar Observation of the Atmosphere. Chicago, IL: Univ. of Chicago Press, 1973

[13] D. L. Livingston, The Physics of Microwave Propagation. Englewood Cliffs, NJ: Prentice-Hall, 1970.

[14] R. K. Crane, Electromagnetic Wave Propagation Through Rain New York: Wiley, 1996.

[15] P. Ferrazzoli and G. Schiavon, "Rain-induced modification of SAR performance," Adv. Space Res., vol. 7, no. 11, pp. 269-272, 1987.

[16] A. Danklmayer, "Propagation effects and polarimetric methods in synthetic aperture radar imaging," Ph.D. dissertation, Tech. Univ. Chemnitz, Chemnitz, Germany, 2008. 
[17] R. L. Olsen, D. V. Rogers, and D. B. Hodge, "The $a R^{b}$ relation in calculation of rain attenuation," IEEE Trans. Antennas Propag. vol. AP-26, no. 2, pp. 318-329, Mar. 1978.

[18] V. N. Bringi and V. Chandrasekar, Polarimetric Doppler Weather Radar, Principles and Applications. New York: Cambridge Univ. Press, 2001.

[19] S. Buckreuß, R. Werninghaus, and W. Pitz, "The TerraSAR-X satellite project," in Proc. IGARSS, Toulouse, France, 2003, pp. 3096-3098.

[20] H. Runge, S. Cloude, M. Eineder, A. Fusco, E. Gill, I. Hajnsek, C. Heer, F. Jochim, M. Kirschner, G. Krieger, A. Moreira, T. Niederstadt, K. Papathanassiou, R. Romeiser, R. Scheiber, C. Sickinger, and S. Suchandt, "New techniques for simultaneous SAR interferometry," Eur. Space Agency, Noordwijk, The Netherlands, Final Rep. ESA Contract 16100/02/NL/EC, 2003.

[21] S. Krämer, "Quantitative Radardatenaufbereitung für die Niederschlagsvorhersage und die Siedlungsentwässerung," Ph.D. dissertation, Leibnitz Universität Hannover, Hanover, Germany, 2008.

[22] D. Atlas and R. K. Moore, "The measurements of precipitation with synthetic aperture radar," J. Atmos. Ocean. Technol., vol. 4, no. 3, pp. 368-376, Sep. 1987.

[23] A. P. Pichugin, Y. G. Spiridonov, and A. B. Fetisov, "Spatial structure of liquid precipitation fields in space radar imagery taken at two orthogonal polarizations," Issled. Zemli iz Kosmosa, vol. 7, no. 4, pp. 70-77, 1987.

[24] A. P. Pichugin and Y. G. Spiridonov, "Spatial distribution of rainfall intensity recovery from space radar images," Sov. J. Remote Sens., vol. 8, no. 6, pp. 917-932, 1991.

[25] R. K. Moore, A. Mogli, Y. Fang, B. Beh, and A. Ahamad, "Rain measurements with SIR-C/X-SAR," Remote Sens. Environ., vol. 59, no. 2, pp. 280-293, Feb. 1997.

[26] F. S. Marzano and J. A. Weinman, "Inversion of spaceborne X-band synthetic aperture radar measurements for precipitation remote sensing over land," IEEE Trans. Geosci. Remote Sens., vol. 46, pt. 1, no. 11, pp. 3472-3487, Nov. 2008.

[27] J. A. Weinmann and F. S. Marzano, "An exploratory study to derive precipitation over land from X-band synthetic aperture radar measurements," J. Appl. Meteorol. Climatol., vol. 47, no. 2, pp. 562-575, Feb. 2008.

[28] J. Simpson, C. Kummerow, W.-K. Tao, and R. F. Adler, "On the Tropical Rainfall Measuring Mission (TRMM)," Meteorol. Atmos. Phys., vol. 60, no. 1-3, pp. 19-36, Mar. 1996

[29] A. Danklmayer, "Analysis of propagation effects during the external calibration," DLR, Cologne, Germany, Tech. Rep. TX-IOCS-TN-PN-4312, 2006. Available through special permission.

[30] M. Schwerdt, D. Hounam, J. L. Alvarez-Pérez, and T. Molkenthin, "The calibration concept of TerraSAR-X: A multiple mode high resolution SAR,” Can. J. Remote Sens., vol. 31, no. 1, pp. 30-36, Feb. 2005.

[31] M. Schwerdt, B. Bräutigam, M. Bachmann, and B. Döring, "Efficient calibration and first results of TerraSAR-X," in Proc. Adv. SAR Workshop, Vancouver, BC, Canada, 2007.

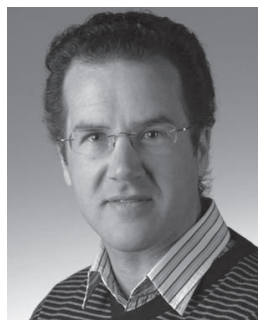

Andreas Danklmayer (S'06-M'08) received the Dipl.-Ing. degree in electronics and communication engineering from the Graz University of Technology, Graz, Austria, in 2002 and the Dr.-Ing. degree in electrical engineering from the Chemnitz University of Technology, Chemnitz, Germany, in 2008.

In 2003, he was granted a European Union Research Fellowship and worked as a young Scientist within the European AMPER (Application of Multiparameter Polarimetry in Environmental Remote sensing) Project at the Microwaves and Radar Institute, German Aerospace Center (DLR), Oberpfaffenhofen, Germany, where he has been with the propagation and scattering group. Since 2006, he was involved in several projects related to microwave remote sensing and atmospheric effects on airborne and spaceborne SAR and particularly on TerraSAR-X. His research interests include atmospheric effects on synthetic aperture radar, Earthspace propagation analysis, basic and applied radar polarimetry, and radar meteorology.

Dr. Danklmayer is an overseas member of the Institute for Electronics and Communication Engineering of Japan and a member of the German ITG Commission on Wave Propagation (FA 7.5). In 2007, he received the Student Paper Contest Prize at the International Symposium on Antennas and Propagation, Niigata, Japan.

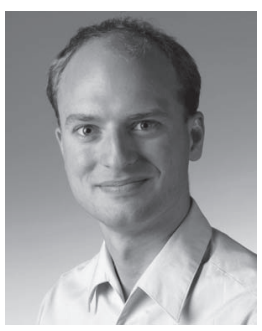

Björn J. Döring received the Dipl.-Ing. degree in electrical engineering from the Technical University Berlin, Berlin, Germany, in 2005.

Since 2006, he has been with the Microwaves and Radar Institute, German Aerospace Center (DLR), Oberpfaffenhofen, Germany. He is working on satellite SAR calibration and was heavily involved in the calibration of TerraSAR-X

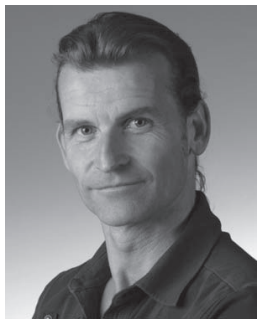

Marco Schwerdt received the Dipl.-Ing. degree in electrical engineering and the Doctorate (Dr.-Ing.) degree, with a thesis on electrooptical E-field sensors, from the Technical University of Berlin, Berlin, Germany.

Since 1998, he has been with the Microwaves and Radar Institute, German Aerospace Center (DLR), Oberpfaffenhofen, Germany, working on SAR calibration methods and performance analysis tools Since 2000, he has been the Head of the Radar Calibration Group, performing various radar calibration activities for different SAR missions like XSAR/SRTM or the ScanSAR mode of ASAR/ENVISAT. He is responsible for the successful calibration of the entire SAR system of the German TerraSAR-X satellite mission, launched in 2007. Currently, all preparations are made to calibrate the TanDEM-X system. Furthermore, as part of the Global Monitoring Environment and Security Program, he is responsible for developing the overall SAR system calibration and validation plan for ESA's Sentinel-1 mission. Under his leadership, the DLR's comprehensive radar calibration facilities, including novel tools for product quality control and performance analysis, have been maintained and extended. His major research interest includes the development of innovative and efficient calibration methods.

Dr. Schwerdt received the Award "Der Deutsche Gründerfonds" in 1997 for establishing an enterprise of manufacturing electrooptical field sensors under the patronage of the German Federal Minister for Science and Research.

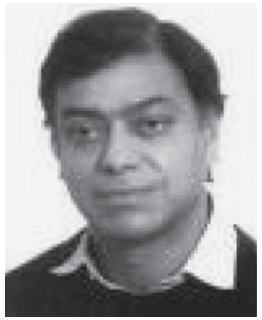

Madhu Chandra received the B.Sc. degree from the University of London, London, U.K., in 1978 and the $\mathrm{Ph} . \mathrm{D}$. degree from the University of Salford, Salford, U.K., in 1981.

In 1980, he joined the Department of Electrical Engineering, University of Bradford, Bradford, U.K., as a Member of the academic staff. In 1984, he was with the Microwaves and Radar Institute, German Aerospace Center (DLR-HR), Oberpfaffenhofen, Germany, where he worked on radar and propagation topics. Since April 2002, he has been the Head of the Department of Microwave Engineering and Photonics, Chemnitz University of Technology, Chemnitz, Germany, where he is also currently the Departmental Chair and the Vice Dean of the faculty.

Prof. Chandra chairs the German ITG Commission on Wave Propagation (FA 7,5) and is currently the National (German) and International URSI Commission F Chairman. He received the Best Paper Award on Propagation at the IEEE International Conference on Antennas and Propagation, Warwick, U.K., in 1985. 